\title{
Anesthesia for elite athletes: a systematic literature review
}

\section{Bram Bourgonjon ${ }^{1}$, Kris Vermeylen ${ }^{2}$, Niek Tytgat ${ }^{3}$, Frank Pauwels ${ }^{1}$, Patrice Forget ${ }^{1}$, Jan Poelaert ${ }^{1}$}

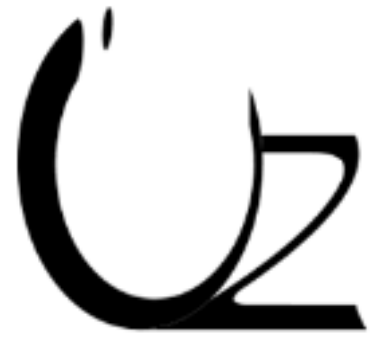

\section{Universitair Ziekenhuis Brussel}

VRIJE UNIVERSITEIT BRUSSEL

\section{Introduction}

Anesthesiologists are increasingly confronted with athletes in a perioperative setting. The right choice of type of anesthesia technique, pain management of injuries, specific physiologic adaptations of the athlete and knowledge of prohibited substances are eminent for a correct approach of this subpopulation. In this poster we present the most important topics of a systematic review we conducted.

\section{Cardiovascular adaptations}

An anesthesiologist should recognize the most common benign ECG findings in athletes like bradycardia, isolated left ventricle hypertrophy on voltage criteria and early repolarization as normal features in the athlete's heart. T-wave inversion beyond lead $\mathrm{V}_{2}, \mathrm{Q}$-waves and ST-segment depression should prompt further investigation with a specialized cardiologist, even in asymptomatic athletes. Long-term endurance sport practice also seem to increase the risk for atrial fibrillation. The underlying mechanisms remain to be clarified, although structural atrial changes (dilatation and fibrosis) are probably present. The risk for atrial fibrillation is related to the accumulated hours of practice and therefore mainly presents at a mean age between 40 and 50, after their professional career. Isotonic physiology is characterized by a volume load on all 4 chambers and accompanying great vessels and typically produces chamber dilation. In contrast, isometric stress creates high intravascular pressure leading to increases in systemic blood pressure in excess of $400 \mathrm{mmHg}$. This pressure load is largely focused on the left ventricle, causing left ventricular hypertrophy.
1. UZ Brussel, Anesthesiology \& Sports Medicine

2. AZ Turnhout, Anesthesiology

3. ASZ Aalst, Anesthesiology

\section{Implications of performance-enhancing substances}

Long-term anabolic steroid usage can complicate airway manipulation due to hypertrophy of the deltoid and other neck muscles which can impede neck extension for manual bag ventilation and intubation. Electrolyte disturbances are also possible due to the mineralocorticoid effect of anabolic steroids (e.g. hypernatremia, hypervolemia and hypokalemia). Careful arousal from general anesthesia is necessary because these patients are more prone to psychotic episodes. Protein hormones (e.g. growth hormones) are often used in combination with anabolic steroids and can increase the risk for cardiovascular events, hypertrophy of soft tissues of the mouth and prognathism due to bony proliferation of the mandible, especially in patients with acromegaly.

\section{Prohibited substances during anesthesia}

The World Anti-Doping Agency (WADA) updates annually a list, which identifies "prohibited performance enhancing substances and methods in-and-out of competition", and in particular sports. Some substances are only prohibited in-competition, which is defined as the period commencing 12 hours before competition through to the end of such competition and the sample-collection process related to such competition. If the required medication happens to fall under the prohibited list, a Therapeutic Use Exemption (TUE) may give the athlete the authorization to take this needed medicine. In case of emergency treatment or treatment of an acute medical condition, a TUE may be granted retroactively. The included table can serve as a guide for the safe use of medication during anesthesia, not conflicting with the prohibited list of the WADA.

\begin{tabular}{|l|l|l|}
\hline \multicolumn{1}{|c|}{ Safe } & \multicolumn{1}{|c|}{ Prohibited in-competition } & \multicolumn{1}{c|}{ Prohibited at all times } \\
\hline Propofol & Fentanyl and derivatives & Erythropoietins \\
\hline Ketamine & Morphine & B2-agonists \\
\hline Benzodiazepines & Oxycodone & Diuretics \\
\hline Local anesthetics & Buprenorphine & Albumin \\
\hline Muscle relaxants & Methadone & Dextran \\
\hline Paracetamol & Pethidine & Colloids \\
\hline Non-Steroidal Anti-Inflammatory & Pentazocine & Mannitol \\
\hline Drugs & & \\
\hline Tramadol & Cannabinoids & Insulin \\
\hline Codeine & Glucocorticoids & \\
\hline Antibiotics & Ephedrine & \\
\hline & Epinephrine & \\
\hline
\end{tabular}

